\title{
Motivação e eficiência em estratégias de ensino de física no nível médio
}

\author{
Motivation and efficiency in high school physics teaching strategies \\ Orildo Luis Battistel ${ }^{1,2}$, Sheila Magali Holz ${ }^{* 1,2 @}$, Ines Sauerwein ${ }^{1}$ \\ ${ }^{1}$ Universidade Federal de Santa Maria, Santa Maria, RS, Brasil. \\ ${ }^{2}$ Colégio Militar de Santa Maria, Santa Maria, RS, Brasil.
}

\begin{abstract}
Recebido em 03 de agosto de 2021. Revisado em 14 de novembro de 2021. Aceito em 13 de dezembro de 2021.
O presente estudo teve como objetivo analisar como os alunos avaliam as cinco estratégias de ensino escolhidas e utilizadas pelos professores nas aulas de Física. Além de verificar quais as estratégias eles consideram mais motivadoras e mais eficientes, buscamos explicitar a orientação motivacional dos mesmos. O instrumento utilizado foi constituído por questões fechadas, respondidas por meio de uma escala Likert, e questões abertas, dissertativas. Para a análise dos dados da pesquisa nos baseamos na Análise de Conteúdo, desenvolvida por Bardin. Verificamos que a estratégia de ensino considerada a mais motivante é a aula prática de laboratório, enquanto as mais eficientes são a aula de resolução de problemas/exercícios e a aula expositiva com quadro branco. No que se refere à orientação motivacional, os dados indicam que a motivação apresentada pelos alunos possui elementos em um amplo espectro, envolvendo diferentes categorias de motivação intrínseca e de motivação extrínseca.
\end{abstract}

Palavras-chave: Motivação, Física, Ensino médio, Estratégias de ensino.

This study aims at analyzing how the students evaluate the five teaching strategies that have been chosen and used by the teachers in the Physics classes. In addition to verifying which strategies are considered more motivating and efficient, it aims at explaining students' motivational orientation. The instrument used consisted of closed questions, answered by a Likert scale, and open ones. The analysis of the data is based on the Content Analysis developed by Bardin. It was verified that the teaching strategy considered the most motivating is the laboratory practical class, while the most efficient ones are the problem/exercises solving class and the expository class whit whiteboard. Regarding motivational orientation, the data indicate that the motivation presented by the students has elements in a broad spectrum, involving different categories of intrinsic and extrinsic motivation. Keywords: Motivation, Physics, High school, Teaching strategies.

\section{Introdução}

O grande desafio apresentado aos profissionais da educação é o de conduzir de maneira apropriada o aprendizado nas escolas brasileiras para responder às transformações sociais e culturais da nossa sociedade. Vive-se em uma esfera globalizada e sujeita a diversas influências que podem de uma forma ou de outra desvirtuar esse processo.

Parece haver, no entanto, uma falta de sintonia entre a realidade escolar e as necessidades formativas dos alunos. Quando o professor estrutura o seu fazer pedagógico por meio de atividades adequadamente planejadas, identificando as competências que busca desenvolver e quais prioridades norteiam o uso dos recursos materiais e a distribuição da carga horária, é que ele compreende a relevância do seu trabalho e da sua disciplina para que as metas gerais formativas sejam atingidas.

\footnotetext{
* Endereço de correspondência: holz_sheila@yahoo.com.br
}

Diferentes propostas têm sido apresentadas com o objetivo de desenvolver práticas pedagógicas mais adequadas e que propiciem um aprendizado mais eficiente. De acordo com Silva, Neto e Carvalho [1, algumas dessas novas concepções têm apenas melhorado o discurso dos professores, sem alterar as suas práticas. Porém, há inúmeras situações em que se verifica que a partir do trabalho dos pesquisadores são propostos modelos de aprendizagem que se tornam subsídios teóricos para a proposição de estratégias de ensino, currículos e material de apoio.

Nesse contexto, entendemos que há dois aspectos importantes que o professor deve analisar e considerar ao nortear o seu trabalho: a motivação dos alunos e a eficiência do ensino ministrado.

\section{Motivação e Eficiência}

Apesar da complexidade que envolve e dos fatores subjetivos associados à motivação, cada professor pode desenvolver, a partir de sua experiência, diversas maneiras de analisar o quão motivante está sendo a sua 
aula e as atividades que propõe aos alunos. Com relação às inúmeras pesquisas e trabalhos originados a respeito do tema, é possível afirmar que a motivação escolar é um dos fatores mais importantes para a determinação daquilo que vai ser ou não aprendido. Está muito claro que um aluno não estuda e se dedica espontaneamente a um conteúdo que não lhe chame atenção, que não desperte o seu interesse, que não faça perceber a pertinência ou o seu significado. Quando o conteúdo tem essas características ele acaba sendo aprendido de forma literal e arbitrária [2].

Para Pintrich e Schunk [3], a motivação deve ser analisada como um processo e não um produto, de modo que deveria ser observada apenas de forma indireta, a partir dos comportamentos dos indivíduos. Estes indivíduos possuem sempre os seus objetivos específicos os quais orientam suas ações, estabelecendo aquilo que os atrai e o que pretendem evitar. Esta especificidade também está presente na ideia de Murray [4, que afirma ser a motivação um fator interno que dá início, dirige e integra o comportamento de uma pessoa.

As abordagens a respeito da motivação na literatura em ensino têm sido apresentadas dividindo-a em duas categorias: a extrínseca e a intrínseca [5]7]. A motivação extrínseca é caracterizada pela busca de respostas externas à tarefa ou atividade realizada. Ela envolve a expectativa de obtenção de recompensas materiais ou sociais e da ocorrência de determinadas consequências, positivas ou negativas. No contexto escolar envolve a aprovação do professor e de pares e a necessidade de promoção, no sentido que o aluno espera receber elogios e ser recompensado por uma nota alta, por exemplo. Além disso, busca atender demandas ou pressões de outras pessoas e, ainda, demonstrar competências e habilidades [7, 8].

A motivação intrínseca, por outro lado, se refere à execução da tarefa ou atividade pelo prazer que esta pode proporcionar sem a necessidade de pressões externas e de prêmios, recompensa ou notas. Neste caso, o indivíduo busca a consecução da atividade por esta ser interessante, envolvente, atraente e por gerar satisfação pessoal. Essa forma de motivação é considerada preponderante em relação ao engajamento e por potencializar o processo de aprendizagem. Ela promove no aluno a busca por desafios, satisfação da curiosidade e julgamento autônomo em tarefas escolares fortalecendo a motivação para aprender. O aluno intrinsecamente motivado procura oportunidades para exercitar novas habilidades e envolve-se em atividades que proporcionam um sentimento de competência e autonomia [7].

Os autores da denominada Teoria da Autodeterminação 9] identificaram três características ou processos cognitivos pelos quais fatores ambientais afetam e são determinantes para a motivação intrínseca. Eles as caracterizaram como necessidades básicas do ser humano: de competência, de autonomia e de vínculo ou relacionamento. De modo semelhante, Martinez e
Haertel [10] agrupam em três dimensões o interesse na aprendizagem de sujeitos intrinsecamente motivados: apelo cognitivo, apelo à maestria e apelo social. No contexto escolar, essas abordagens buscam relacionar os elementos presentes em alunos que se percebem como o centro de suas ações, ao invés daqueles que agem sob influências de agentes externos, quer por meio de pressões, quer por meio de recompensas.

Em trabalho de investigação relacionado à motivação escolar, Laburú 11 analisou a possibilidade de potencializar a motivação por meio da utilização de atividade práticas interessantes, que ele denominou "experimentos cativantes". Como mostra o autor, essa é uma das possibilidades que o professor de ciências tem ao seu alcance para prender atenção dos alunos em sala de aula. Partindo de uma reformulação e redefinição de conceitos relacionados à teoria da motivação, ele fundamenta e orienta a elaboração de atividades experimentais para a disciplina de Física, que contemplem esses aspectos e tragam embutidos em seu planejamento o objetivo de disparar a motivação da aprendizagem.

Neste ponto, uma questão importante, como nos aponta Laburú [1], é se a falta de motivação apresentada por alguns alunos é devida unicamente a causas ou consequências de alguma dificuldade apresentada pelo aluno ou por falhas de planejamento ou utilização, por parte do professor, de estratégias que não são capazes de chamar e prender a atenção do aluno, de estimulá-lo suficientemente para empregar maior energia na realização das atividades, de querer saber mais sobre o assunto, enfim, de adotar uma postura de autonomia frente ao estudo, mesmo quando os temas abordados são menos atraentes e mais complicados.

O que se pode dizer em relação a esse questionamento é que certamente há uma relação de causa e efeito entre o trabalho do professor e a motivação do aluno, inclusive com uma indiscutível reciprocidade e esse aspecto é muito importante e intensifica a determinação e a persistência do primeiro, na adoção de estratégias potencialmente motivacionais, estimuladas pelo efeito que promovem no segundo, ou seja, a aprendizagem.

No modelo tradicional, a concepção de aprendizagem é a de um processo acumulativo por meio de propostas didáticas transmissoras e uniformizadoras e está relacionada a uma avaliação de caráter sancionador, centrada exclusivamente nos resultados, sendo uma maneira seletiva de reconhecer os alunos mais preparados [12].

É nessa conjuntura que estabelecemos a conexão entre a motivação e o outro aspecto do ensino que investigamos neste trabalho: a sua eficiência.

Entendemos que analisar a eficiência nos remete à questão da avaliação, com toda a complexidade envolvida no tema e nos faz recorrer a conceitos e suscitar desdobramentos que, apesar de muito pertinentes, estão além do escopo do nosso estudo mais sintético pretendido neste momento. No entanto, mesmo para uma abordagem com essas características, temos que ressaltar 
que, quando nos referimos aos objetos da avaliação, há basicamente dois processos sujeitos a avaliação e indissociáveis: o que diz respeito à forma que o aluno aprende e o que se refere a como o professor ensina, comumente relacionados aos processos de aprendizagem e de ensino, respectivamente.

Desta discussão fica evidente a inter-relação entre os processos de ensino e aprendizagem e que é importante e necessário, além de analisar e avaliar a aprendizagem, que busquemos encontrar elementos que nos deem indicações a respeito do processo de ensino propriamente dito. Neste sentido, damos ênfase em buscar saber em que medida essas estratégias e as inerentes atividades propostas são eficientes em promover aquilo que seria o objetivo do ensino que ministramos, sem, no entanto, traduzir exclusivamente em notas e qualificações tradicionais.

Um elemento que entendemos importante nesse cenário e que pode ter um importante papel no estabelecimento das relações estudadas, é o da análise da eficiência do ponto de vista do aluno.

Neste trabalho investigamos de que forma os alunos avaliam algumas estratégias didáticas que têm sido utilizadas nos contextos de sala de aula, a partir das perspectivas da motivação e da eficiência. Para os alunos que participaram da pesquisa procuramos demonstrar que não se tratava de uma avaliação geral do ensino, da escola ou do desempenho do professor. A intenção a eles informada foi de que se solicitava unicamente a sua manifestação em relação às estratégias que o professor utilizou para que eles aprendessem, com o objetivo de buscar subsídios para rever e/ou repensar no âmbito dos planejamentos, a utilização das mesmas, caso necessário.

\section{As Estratégias de Ensino}

Para Zabala [12, o processo de avaliação da intervenção pedagógica deve ser realizado dinamicamente a partir de um modelo de percepção da realidade da aula, vinculando o planejamento, a aplicação e avaliação. Nesta visão processual da prática, as atividades concentram a maioria das variáveis educativas que intervém na aula, podendo assumir diferentes valores umas em relação às outras, a critério do professor. As sequências de atividades ou sequências didáticas seriam "um conjunto de atividades ordenadas, estruturadas e articuladas para a realização de certos objetivos educacionais, que têm um princípio e um fim conhecidos tanto pelos professores como pelos alunos". Estas sequências permitem explicitar a função de cada uma das atividades na construção do conhecimento e podem se utilizar de diversos materiais curriculares e recursos didáticos, com diferentes papéis e importância nas diferentes formas de intervenção.

De acordo com Anastasiou e Alves [13, as estratégias visam a consecução de objetivos, devendo-se ter clareza sobre onde se pretende chegar. Por isso, os objetivos que norteiam o processo de ensino devem estar claros para os professores e para os alunos. Por meio delas é que se aplicam meios, modos, jeitos e formas de evidenciar o pensamento, respeitando as condições favoráveis para executar ou fazer algo, sendo assim, o conhecimento do aluno é essencial para a escolha da estratégia.

Com este sentido, a aula expositiva dialogada [13] é uma estratégia de ensino ou intervenção pedagógica com adequada aplicabilidade, sobretudo em relação ao ensino de conteúdos factuais e conceituais em que estão em jogo atividades que visam, sobretudo, informar. Neste contexto, são úteis os recursos de suporte que podem contribuir para a explicação, como o quadro branco, o livro didático e os meios audiovisuais. Além disso, mais do que tolerada, a participação efetiva do aluno é estimulada e valorizada: suas contribuições são sempre respeitadas, analisadas e contextualizadas. Propicia-se um clima de cordialidade, parceria e intensa troca.

Uma estratégia de ensino muito citada por professores da área de ciências é a que faz uso de laboratório didático, em que se procura desenvolver as denominadas atividades práticas, onde os alunos experimentam realizando atividades por meio de instrumentos e materiais concretos, em geral aplicando um conhecimento já abordado de forma teórica, ou com diferentes finalidades e objetivos, visando sempre a consecução destes a partir de planejamentos elaborados previamente.

A importância das atividades práticas como facilitadoras da aprendizagem é discutida por Borges [14], identificando a melhor forma de utilização das mesmas. O autor destaca a necessidade de um planejamento rigoroso de tais atividades, em que sejam levados em conta os objetivos pretendidos, os recursos disponíveis e as ideias prévias dos alunos sobre o assunto em estudo. Recomenda que se dê ênfase especial na caracterização de atividades práticas para fins pedagógicos, diferentemente da investigação experimental realizada por cientistas, deixando bastante claras as limitações que determinados equipamentos podem apresentar sobre os resultados dos experimentos. Além disso, não pode faltar uma discussão sobre os resultados obtidos.

Em outra abordagem inovadora, pesquisas têm sido desenvolvidas no sentido de situar a utilização de novas tecnologias de informação e comunicação (TIC) na educação. Fiolhais e Trindade [15] destacam o desenvolvimento de novas gerações de computadores e de dispositivos de comunicação que, além das suas magníficas qualidades gráficas, têm a grande vantagem da portabilidade. Esses meios tecnológicos oferecem novas perspectivas educacionais que devem ser desenvolvidas e avaliadas. Em seu estudo, esses autores destacam a inserção das TIC e dos computadores no ensino de ciências e da Física, especialmente, nas seguintes situações: aquisição de dados por computador, modelagem e simulação, multimídia, realidade virtual e internet.

Uma destas possibilidades são as Simulações Interativas do Projeto PhET [16] da Universidade de Colorado (EUA), onde são criadas simulações interativas de 
matemática e ciências. Como indicam os responsáveis pelo projeto, elas foram desenvolvidas para serem divertidas e buscam envolver os alunos através de um ambiente intuitivo, estilo jogo, onde os alunos aprendem através da exploração e da descoberta. Podem ser executadas on-line ou copiadas para os computadores dos usuários e têm código aberto, permitindo que estes recursos sejam livres para estudantes e professores. Os estudantes ao utilizarem as ferramentas, recebem feedback em tempo real podendo analisar as variações nos parâmetros e investigar os seus efeitos nos fenômenos estudados.

A Resolução de Problemas é outra opção de estratégia de ensino, amplamente utilizada por professores de ciências e matemática.

Conforme Echeverría e Pozo [17], a aprendizagem por meio da resolução de problemas, enquanto objetivo educacional, tem sido vista como uma forma de motivar o aluno a propor-se problemas constantemente e a procurar as respostas como forma de aprender. Para tanto, os problemas precisam ser abertos, diferentes uns dos outros e imprevisíveis, de modo que o aluno possa recorrer à sua bagagem de conceitos e procedimentos. As atividades propostas devem implicar um processo de reflexão, de planejamento e tomada de decisão, estabelecendo-se uma verdadeira estratégia de solução de problemas.

A importância do desenvolvimento de técnicas de resolução está na própria definição de problema elaborada por Echeverría e Pozo [17]. Segundo os autores um problema é uma situação que um indivíduo ou grupo quer e precisa resolver e para a qual não dispõe de um caminho rápido e direto que o leve à solução. Quando a prática levar a uma solução direta e eficaz, ou quando se tenha adquirido habilidade suficiente para, com um reduzido esforço mental, conseguir realizar a tarefa e a solução puder ser aplicada de forma rotineira, então o problema terá se reduzido a um exercício. Mesmo assim, quando se trata de conhecimento escolar, é sempre importante exercitar as habilidades adquiridas, principalmente porque a partir disso é possível avançar para estágios superiores de resolução de problemas por meio de analogia e generalização.

\section{Metodologia}

O trabalho apresentado é fruto de uma pesquisa de natureza aplicada e descritiva, pois descreve fatos e fenômenos de uma determinada realidade [18. Ela tem uma abordagem predominantemente qualitativa, uma vez que os pesquisadores estudam as coisas no seu "setting" natural tentando dar sentido ou interpretar fenômenos em termos dos significados que as pessoas trazem [19].

Para a análise dos dados da pesquisa nos baseamos na Análise de Conteúdo, que é uma técnica desenvolvida por Bardin [20] e que tem sido amplamente utilizada em estudos de mesma natureza. Segundo a autora, designase sob o termo Análise de Conteúdo:

um conjunto de técnicas de análise das comunicações visando obter, por procedimentos sistemáticos e objectivos de descrição do conteúdo das mensagens, indicadores (quantitativos ou não) que permitam a inferência de conhecimentos relativos às condições de produção/recepção (variáveis inferidas) destas mensagens [20, p. 37].

O estudo do contexto social requer conceitos sensibilizadores, uma vez que o sujeito e o objeto de observação são inseparáveis e os fatos e os valores são intrinsecamente ligados devendo predominar uma lógica indutiva, do particular para o geral 21. Desta forma, os dados provenientes das pesquisas qualitativas precisam ser analisados de forma diferente dos dados provenientes de estudos quantitativos, sendo a análise de conteúdo bastante apropriada e adequada para esta finalidade 22.

Como afirmam Denzin e Lincoln [19, a pesquisa qualitativa pode recorrer a várias metodologias para a busca de dados em uma investigação, sem privilegiar esta ou aquela técnica de pesquisa e que é difícil enquadrá-la em um único terreno de discussões havendo múltiplos paradigmas teóricos que alegam empregar os seus métodos e estratégias. Segundo esses autores, os pesquisadores qualitativos utilizam a análise semiótica, a análise da narrativa, do conteúdo, do discurso, de arquivos e a fonêmica e até mesmo as estatísticas, as tabelas, os gráficos e os números. Este uso de múltiplos métodos, a denominada "triangulação", reflete uma tentativa de assegurar uma compreensão em profundidade do fenômeno em questão, constituindo-se em alternativa para se empreender múltiplas práticas metodológicas, perspectivas e observadores em uma mesma pesquisa, o que garante rigor, riqueza e complexidade ao trabalho.

De acordo com Bardin [20], enquanto a abordagem quantitativa funda-se na frequência de aparição de certos elementos da mensagem, a abordagem qualitativa recorre a indicadores não frequenciais suscetíveis de permitir inferências. Esta última funciona bem sobre corpus reduzidos, estabelecendo categorias mais discriminadas enquanto a primeira está ligada a categorias que dão lugar a frequências suficientemente altas para que os cálculos se tornem possíveis. Segundo ela a análise de conteúdo até a primeira metade do século XX era marcada pelo rigor e, portanto, pela quantificação sendo posteriormente compreendido que a sua característica é a inferência, quer as modalidades de inferência se baseiem ou não em indicadores quantitativos.

A nossa estratégia de triangulação articula uma parte da pesquisa de característica quantitativa, cujo instrumento de pesquisa é o questionário fechado de múltipla escolha, cujos resultados são analisados por meio de operações estatísticas simples, em que são avaliados percentuais de respostas nestas questões, e uma outra 
parte qualitativa com base em respostas nas perguntas abertas contidas no mesmo. Nessa triangulação de dados, os respondentes do instrumento quantitativo e qualitativo da pesquisa foram abordados no mesmo momento. A amostra foi constituída por 98 alunos de um estabelecimento público de ensino da cidade de Santa Maria, no Rio Grande do Sul. Os referidos alunos cursavam o segundo ano do ensino médio, e estavam divididos em quatro turmas.

O questionário foi composto por 11 questões fechadas nas quais os alunos deveriam avaliar as cinco estratégias de ensino mais utilizadas pelos professores durante os dois primeiros trimestres letivos de 2018 e parte do terceiro trimestre do mesmo ano. Nas primeiras 10 questões, cada estratégia de ensino deveria ser avaliada de acordo com o nível de motivação que esta desperta para o estudo dos conteúdos abordados na disciplina de Física e também em relação à sua eficiência na aprendizagem desses conteúdos. Essa avaliação foi realizada a partir de uma escala Likert de cinco pontos que era interpretada numericamente por um índice que variava entre (1) e (5), sendo (1) pouco motivante/eficiente e (5) extremamente motivante/eficiente. Essas respostas foram denominadas espontâneas ou não comparativas. Finalmente, na questão 11 eles foram convidados a colocar em ordem de importância, em relação à motivação e também à eficiência, as cinco estratégias de ensino, considerando também uma escala Likert, variando de (1) a (5), sendo (1) a menos motivante/eficiente e (5) a mais motivante/eficiente. Estas respostas foram denominadas comparativas.

A parte aberta e dissertativa do questionário foi constituída de espaços onde os alunos poderiam tecer comentários em relação às estratégias de ensino, analisando e avaliando cada uma delas. Esses comentários não foram limitados e nem orientados por qualquer tipo de direcionamento, estando livre a manifestação. A intenção era a de verificar quais as estratégias os alunos consideram mais motivadoras e mais eficientes, para os conteúdos de Física e explicitar, na medida do possível, qual a orientação motivacional dos mesmos ao desenvolverem as atividades propostas nessas estratégias.

De acordo com as etapas propostas por Bardin [20], os dados colhidos na pesquisa, por meio da parte aberta do instrumento utilizado, foram submetidos a uma préanálise, partindo de uma leitura flutuante, escolha de documentos, formulação de hipóteses e elaboração de indicadores. A seguir procedemos à etapa de codificação, promovendo-se recortes do material em unidades de registro, dando início às categorizações e, finalmente, passamos a inferência ou interpretação a partir das categorias construídas no trabalho, procurando-se captar os conteúdos explícitos e implícitos no sentido de obterse uma compreensão e dar significação às mensagens oriundas desse procedimento.

A seguir apresentamos os resultados decorrentes da investigação realizada e as discussões que os mesmos suscitaram, à luz do referencial teórico que adotamos.

\section{Resultados e Discussões}

Iniciando esta apresentação pela parte quantitativa da pesquisa, ou seja, com base na análise das respostas dos alunos ao nosso questionário, nas questões de 1 a 11 , que eram constituídas de questões fechadas, foi possível obter-se as tabelas 1 e 2 apresentadas a seguir. Inicialmente, na Tabela 1 estão os resultados das questões de 1 a 10, obtidos por meio da utilização de uma escala de Likert, como mencionado anteriormente. A partir dos valores atribuídos pelos alunos respondentes foram calculadas as médias aritméticas dos índices obtidos por cada estratégia nos quesitos de motivação e eficiência.

A Tabela 1 nos mostra que a aula prática de laboratório é a atividade mais bem avaliada no quesito motivação, seguida pela aula expositiva com quadro branco. No quesito eficiência a aula de resolução de problemas/exercícios é a que obtém a melhor avaliação, seguida da aula expositiva com quadro branco, tendo a primeira obtido resultados levemente superiores aos da segunda. Estas estratégias poderiam ser consideradas empatadas, dados os valores numéricos muito próximos obtidos por elas neste quesito.

Na Tabela 2 apresentamos os resultados obtidos como resposta à questão 11 do questionário, a qual tinha como objetivo obter uma ordenação das referidas estratégias, com intuito de classificá-las, de modo comparativo, segundo a opinião dos alunos. Esta questão foi incluída com o intuito de ratificar ou explicitar divergências nos resultados obtidos nas questões de 1 a 10 , nas quais as estratégias eram avaliadas separadamente.

Os resultados apresentados na Tabela 2 permitem verificar que as estratégias mais bem avaliadas, no quesito de motivação, são novamente a aula prática de laboratório e a aula expositiva com quadro branco, enquanto que, no quesito eficiência, as estratégias com

Tabela 1: Comparação das médias registradas pelas diferentes estratégias de ensino nas dimensões motivação e eficiência respostas espontâneas.

\begin{tabular}{lcc}
\hline Estratégia & Motivação & Eficiência \\
\hline Aula expositiva com quadro branco & 3,827 & 4,439 \\
Aula expositiva com Datashow & 3,020 & 3,388 \\
Aula prática de Laboratório & 4,582 & 4,204 \\
Aula com simulação interativa PhET & 3,735 & 3,633 \\
Aula de resolução de problemas/exercícios & 3,633 & 4,541 \\
\hline
\end{tabular}

Tabela 2: Comparação das médias registradas pelas diferentes estratégias de ensino nas dimensões motivação e eficiência respostas comparativas.

\begin{tabular}{lcc}
\hline Estratégia & Motivação & Eficiência \\
\hline Aula expositiva com quadro branco & 3,133 & 3,684 \\
Aula expositiva com Datashow & 2,184 & 2,429 \\
Aula prática de Laboratório & 4,214 & 3,153 \\
Aula com simulação interativa PhET & 2,520 & 1,980 \\
Aula de resolução de problemas/exercícios & 2,908 & 3,735 \\
\hline
\end{tabular}


melhores índices são também a aula de resolução de problemas/exercícios e a aula expositiva com quadro branco, tendo essas duas, da mesma forma que na Tabela 1, obtido resultados numéricos muito próximos.

$\mathrm{Na}$ busca de procurar entender e contextualizar esses resultados, procuramos nas respostas da parte qualitativa as opiniões e os comentários emitidos pelos alunos para justificar as suas preferências relativas às atividades analisadas. Posteriormente realizaremos uma análise mais sistemática desses dados.

Em relação à motivação, os dados mostram que a aula prática de laboratório é bem avaliada pelos alunos, tendo como justificativas principais o fato de envolverem atividades diferentes, empolgantes, interativas, realizada em ambiente diferente e que permite relacionar a teoria com a prática. Quanto à aula expositiva com quadro branco, os dados mostram que elas são consideradas interativas, que permitem a participação dos alunos, permitem o diálogo, conversa informal, que facilitam o estudo em casa a partir das anotações realizadas durante a aula.

No que diz respeito à eficiência os dados indicam que a aula de resolução de problemas/exercícios é associada a promover um direcionamento do conteúdo para as avaliações, por dar indicações de como esses conteúdos serão cobrados e também por estar associada a resolver, entender e treinar. A aula expositiva com quadro branco, por sua vez, por ter o conteúdo no caderno, o que facilita a fixação, por poder contar com os resumos do professor, por ver e fazer junto com este, por permitir anotar do "seu jeito", entre outros motivos expressados pelos alunos.

Em face do exposto, um destaque pode ser feito em função dos resultados verificados em relação a aula expositiva com quadro branco, normalmente associada a uma metodologia tradicional de ensino.

No livro de Bordenave e Pereira [23], escrito no final da década de 70, esses autores caracterizavam um professor "moderno" como aquele que tinha a escolha adequada das atividades de ensino como uma etapa importante de sua profissão. O professor "tradicional", por sua vez, utilizava-se unicamente da exposição oral ou preleção, sem "perder tempo procurando alternativas".

Entendemos que não se deve confundir modelo educativo tradicional com aula expositiva, ou melhor, não com toda aula expositiva. O que costumamos designar aula expositiva dialogada [13, p. 79] é uma exposição do conhecimento, com a participação ativa dos estudantes, cujo conhecimento prévio deve ser considerado e pode ser tomado como ponto de partida. Neste modelo o professor leva os estudantes a questionarem, interpretarem e discutirem o objeto de estudo, a partir do reconhecimento e do confronto com a realidade.

As perspectivas tradicionais, centralizadas no professor, ao qual se atribui o papel de transmissor do conhecimento e controlador dos resultados, restando ao aluno a interiorização do conhecimento, a partir de uma conduta passiva, obediente e de memorização, têm sido bastante criticadas na literatura. Em contraposição se fomentam a adoção de concepções construtivistas nas quais ao aprendiz é propiciado construir uma interpretação pessoal e subjetiva do que é tratado.

Nesse sentido, a aula expositiva tem importante finalidade quando se utiliza de atividades que possibilitem a organização significativa e associações de conhecimentos que favoreçam a tarefa de memorização. Elas podem se utilizar de relações com esquemas ou representações gráficas, formulando analogias, associações entre os conteúdos e outros já assimilados. Quanto ao suporte, o quadro branco, ou o célebre quadro negro, apesar de nunca suficientemente valorizado [12, p. 69] tem ainda um papel preponderante.

Os dados obtidos na pesquisa e apresentados nas tabelas 1 e 2 representam um resgate notável da aula expositiva como estratégia de intervenção pedagógica. Percebemos gratificados que na visão dos alunos há espaço para essa modalidade com destacados resultados tanto na motivação quanto na eficiência do ensino ministrado.

A seguir são descritos com maior detalhamento os resultados obtidos na parte qualitativa do instrumento e a sua análise.

A interpretação dos resultados foi realizada, como já referido, pelo método de análise de conteúdo seguido por Bardin 20. Desta forma realizamos a codificação em função da repetição de palavras presentes nos discursos escritos e de trechos selecionados das falas dos participantes, assim constituindo as unidades de registro e posteriormente efetuando a categorização. Do agrupamento progressivo das categorias, fundamentadas nas narrativas dos participantes, das observações in loco realizadas pelos pesquisadores e sob a ótica do referencial teórico, emergiram as quatro categorias finais apresentadas no Quadro 1

$\mathrm{Na}$ sequência destacamos os elementos mais importantes obtidos a partir da análise dos resultados e das evidências coletadas nas respostas. Procuramos, por meio de inferência e interpretação desses resultados dar relevo às informações emanadas e, na medida do possível, confrontá-las com o referencial teórico que adotamos e propiciaram o contexto para a análise do conteúdo. Optamos por apresentar uma descrição das categorias finais construídas no trabalho.

\subsection{A motivação intrínseca proporcionada pela curiosidade, a fantasia e o lúdico}

De acordo com as manifestações dos alunos abordados pela pesquisa, entre as atividades didáticas que mais lhes chamam a atenção e lhes despertam maior interesse em participar ativamente, estão aquelas que são geradoras de satisfação pessoal. Atividades que tenham, sobretudo, aspectos de descontração e lembrem a forma de brincar e interagir com os colegas. Tais atividades precisam ter um caráter de novidade, algo que não tenha a ver com 
Quadro 1: Categorias de análise.

\begin{tabular}{|c|c|c|}
\hline Categorias Iniciais & Categorias Intermediárias & Categorias Finais \\
\hline Prendem a atenção & \multirow{7}{*}{ I. Atividades com ênfase ao lúdico } & \multirow{15}{*}{$\begin{array}{l}\text { I. A motivação intrínseca } \\
\text { proporcionada pela curiosidade, } \\
\text { a fantasia e o lúdico. }\end{array}$} \\
\hline Aula descontraída & & \\
\hline Desafio & & \\
\hline Brincar/interagir & & \\
\hline Aulas divertidas & & \\
\hline Empolgantes & & \\
\hline Aulas diferentes & & \\
\hline Sair da rotina & \multirow{3}{*}{ II. Atividades em ambientes diferenciados } & \\
\hline Fora da sala de aula & & \\
\hline Ambiente diferente & & \\
\hline Aplicações & \multirow{5}{*}{$\begin{array}{l}\text { III. Atividades que associam textos, } \\
\text { imagens, animações e simulações }\end{array}$} & \\
\hline Imagens & & \\
\hline Visualizar & & \\
\hline Interativa & & \\
\hline Participação dos alunos & & \\
\hline Retirar dúvidas com o professor & \multirow{7}{*}{$\begin{array}{l}\text { IV. Atividades que proporcionam o contato } \\
\text { interpessoal, a interação professor/aluno e } \\
\text { entre pares }\end{array}$} & \multirow{7}{*}{$\begin{array}{l}\text { II. A motivação intrínseca } \\
\text { ligada ao relacionamento } \\
\text { interpessoal. }\end{array}$} \\
\hline Ver e fazer junto com o professor & & \\
\hline Interação da turma & & \\
\hline Diálogo & & \\
\hline Conversa informal & & \\
\hline Competição & & \\
\hline Resolver & & \\
\hline Treinar & \multirow{6}{*}{$\begin{array}{l}\text { V. Atividades que proporcionam o } \\
\text { desenvolvimento de habilidade superior e } \\
\text { perícia em relação aos temas. }\end{array}$} & \multirow{8}{*}{$\begin{array}{l}\text { III. A motivação intrínseca } \\
\text { vinculada à maestria e ao } \\
\text { desenvolvimento de habilidades } \\
\text { e competências. }\end{array}$} \\
\hline Entender & & \\
\hline Entendimento do conteúdo & & \\
\hline Compreensão & & \\
\hline Ver o que errei & & \\
\hline Aplicar o que se aprendeu & & \\
\hline Relacionar a teoria com a prática & \multirow{2}{*}{$\begin{array}{l}\text { VI. Atividades que proporcionem a } \\
\text { construção de diferentes representações e } \\
\text { busca da significação. }\end{array}$} & \\
\hline Ver na prática & & \\
\hline Memorizar as fórmulas & \multirow{5}{*}{$\begin{array}{l}\text { VII. Atividades com apelo, compromisso ou } \\
\text { vinculação evidente com o resultado. }\end{array}$} & \multirow{11}{*}{$\begin{array}{l}\text { IV. Aspectos de motivação } \\
\text { extrínseca. }\end{array}$} \\
\hline Assim que será cobrado & & \\
\hline Aprender com os erros & & \\
\hline Ter o conteúdo direcionado & & \\
\hline Facilita o estudo em casa & & \\
\hline Ter o conteúdo no caderno & \multirow{6}{*}{$\begin{array}{l}\text { VIII. Atividades que proporcionem a busca } \\
\text { de superação de dificuldades de } \\
\text { aprendizagem. }\end{array}$} & \\
\hline Copiar ajuda a memorizar/entender & & \\
\hline Resumo feito pelo professor & & \\
\hline Fixação do conteúdo & & \\
\hline Anotar do seu jeito & & \\
\hline Anotar o conteúdo facilita a fixação & & \\
\hline
\end{tabular}

a sua rotina escolar, normalmente vista como uma aula estática em que o professor ensina e eles passivamente ouvem e aprendem.

Quanto mais o ambiente for diferente da sala de aula tradicional, com cadeiras em fileiras e um quadro branco à frente, que normalmente é utilizado para passar o conteúdo que deve ser copiado, estudado e aprendido para ser reproduzido em uma prova, mais dinâmica, empolgante e com maior atenção dos alunos a aula ou atividade será desenvolvida. Além disso, se a atividade contar com a associação de textos, imagens e animações ela terá um potencial para prender a atenção dos mesmos e propiciar um maior interesse em participar e continuar prestando atenção e se dedicando às tarefas relacionadas, realizando exercícios e aplicações do conteúdo estudado.

A adoção de atividades didáticas com perfil capaz de explorar a novidade ou o lúdico, pode ser decisiva para a obtenção de alunos mais propensos à participação em sala de aula e assim promover uma aprendizagem significativa. De acordo com Pintrich e Schunk 3] a motivação intrínseca é favorecida por atividades que promovam o desafio, a curiosidade, controle e a fantasia. Situações que apresentem uma certa complexidade, que estejam vinculadas ao surpreendente, ao inesperado e que permitam a intensa participação do aluno, fornecem incentivo importante e devem ser contempladas nos planejamentos dos professores.

Da mesma forma, os resultados obtidos em nossa pesquisa, condizem com o que expressa Guimarães [7], quando afirma que o aluno obtém gratificação e satisfação ao dominar uma tarefa desafiadora. A curiosidade e a fantasia são estimuladas por atividades que envolvam componente de apelo cognitivo, incluindo a curiosidade sensória, ativada pela variabilidade visual e 
auditiva e a curiosidade cognitiva, por eventos inesperados ou paradoxais.

A utilização de atividades didáticas que tenham a finalidade de prender a atenção do aluno, como analisado por Laburú [11, exploram a novidade e o lúdico. O primeiro por meio do curioso e do inesperado e o segundo pela sensação de prazer ou pelo desafio. O autor descreve atividades experimentais escolares que podem ser utilizadas para explorar a dimensão do interesse que ele denomina por "apelo à satisfação de baixo nível", as quais, segundo ele, instigam a motivação recorrendo ao bizarro, ao chocante, ao lúdico, à magia e à fantasia, tendo esta dimensão uma aproximação direta com o entretenimento. Nessa dimensão, no entanto, a relação cognitiva do sujeito com o objeto experimental permanece restrita ao periférico, ao superficial e aos observáveis, por ser devida a estímulos de um prazer momentâneo. Em nossa análise verificamos que as afirmações do autor estão em conformidade com o que pensam e manifestam os alunos, principalmente em relação às aulas práticas de laboratório.

\subsection{A motivação intrínseca ligada ao relacionamento interpessoal}

Dentre as possibilidades de desenvolvimento de atividades com características de cunho motivacional, percebese, evidentemente que as mais promissoras são as que desenvolvem um senso de equipe ou de trabalho cooperativo. De qualquer forma, sempre que a atividade permita ou proporcione o contato e a interação entre pessoas, principalmente daqueles que se entendem como pertencentes a um grupo, há uma significativa adesão e uma notável necessidade de colaboração. Assim ocorre no ambiente escolar, na grande maioria das situações, principalmente se há a possibilidade de interação com os colegas e com o professor, em ambiente de maior informalidade, que permita o diálogo e a livre manifestação. Essa é claramente uma evidência comprovada por meio do estudo que realizamos.

As possibilidades de interagir, de ser acompanhado pelo professor, de encontrar apoio e colaboração em tempo real, de poder dividir suas preocupações com os pares em relação aos conteúdos esclarecendo suas dúvidas e poder acompanhar a realização de exercícios modelo, de crescer coletivamente são possibilidades de atividades manifestamente apontadas pelos alunos como aquelas que são representativas das que despertam seu interesse e favorecem a motivação para a aprendizagem.

De acordo com Zabala 12 para potencializar a aprendizagem é preciso criar um ambiente seguro e ordenado, com multiplicidade de interações que promovam a cooperação e a coesão do grupo. Tais interações são presididas pelo afeto, que contemplem a possibilidade de se engajar e realizar as modificações oportunas, nas quais convivam a exigência de trabalhar e a responsabilidade de realizar o trabalho autonomamente. Para o autor, é necessário oportunizar situações em que os alunos participem intensamente na resolução das atividades e no processo de elaboração pessoal. Inicialmente, os alunos podem seguir os modelos ou as diferentes ações propostas pelos professores, com uma ajuda intensa por parte desses. Posteriormente, esta ajuda é retirada progressivamente, assegurando a passagem de competências no nível interpessoal, quando todos trabalham juntos, para o nível intrapessoal, quando eles sejam capazes de agir de forma autônoma.

Em relação à componente "social" da motivação, que é discutida por diversos autores [9, 10, percebe-se a importância do papel motivacional do contato interpessoal. Esses autores destacam a importância na aprendizagem da convivência em um meio cooperativo e da satisfação e do prazer produzidos pelo trabalho conjunto. Este apelo social, ou necessidade de pertencer ou se sentir parte de um contexto, de sentir-se amado, aceito, aprovado e estimado, é uma componente importante da motivação que pode ser bem utilizada como fator motivacional, a partir do desenvolvimento de atividades que proporcionem a interação professor/aluno e entre pares.

\subsection{A motivação intrínseca vinculada à maestria e ao desenvolvimento de habilidades e competências}

Outro aspecto, verificado em nossa pesquisa, é que a motivação intrínseca pode ser proporcionada pelas diferentes estratégias de ensino, por meio de atividades desenvolvidas com os alunos, que lhes motivem a ir mais a fundo no estudo dos conteúdos. Nesta categoria destacam-se expressões utilizadas pelos participantes da pesquisa como: resolver, entender, compreender e treinar. Essas ações manifestadas são características de indivíduos focados em desenvolver competências e habilidades e exercitar capacidades adquiridas no âmbito da disciplina de modo a obter um domínio mais completo dos fatos e conceitos, não ficando satisfeitos com um conhecimento apenas superficial dos mesmos.

A predisposição em aprender com seus próprios erros, avaliando-os com critério e buscando compreender em que medida as suas decisões durante a execução de um exercício ou de uma tarefa não foram as mais adequadas, são indícios de que o aluno busca a consecução da atividade considerando-se o centro do processo de aprendizagem. Esse processo de reavaliação das próprias atitudes demonstra também a busca pela autonomia, na medida em que consegue entender quais as escolhas são mais eficientes para resolver o problema, desenvolvendo um método geral ou estratégia de resolução.

Também é possível verificar que as estratégias utilizadas são consideradas motivadoras por permitirem a aplicação daquilo que foi aprendido e possibilitar o relacionamento entre a teoria com a prática, ou, ainda, que possam "enxergar" acontecendo, quando da realização de experimentos, um fenômeno analisado teoricamente ou previsto a partir de tais considerações. Desse modo, percebe-se que a situação se apresenta revestida de 
significado para o aluno, ou seja, ela faz sentido para ele, pois trata-se de algo que "está acontecendo".

De acordo com Martinez e Haertel [10] uma das dimensões da motivação intrínseca é o denominado apelo à maestria, a qual é vista como uma propensão natural do ser humano relacionada ao interesse individual em exercitar capacidades que permitam interagir de modo competente em seu ambiente. Esse conceito também está presente nos estudos de Harter [5], no qual a busca pela maestria é uma componente motivacional. Da mesma forma, a experiência de dominar uma tarefa desafiadora, desenvolvendo competência e autonomia, traz gratificação e satisfação. Um indivíduo, movido por motivação intrínseca, procura oportunidade para exercitar novas habilidades [7].

Também nesta categoria, os dados obtidos na pesquisa estão em consonância com Laburú 11, uma vez que ele mostra que as atividades motivadoras com propriedades baseadas na dimensão do interesse por "apelo à satisfação de alto nível", são utilizadas para instigar a motivação, invocando a maestria, com objetivo de solucionar problemas ou de recorrer à competência intelectual, a fim de controlar o ambiente experimental defrontado. Segundo o autor, é nessa dimensão que se coloca a possibilidade de abstração conceitual.

\subsection{Elementos de motivação extrínseca}

Nesta categoria classificamos as falas dos alunos participantes da pesquisa, nas quais estão presentes elementos que costumam ser caracterizados como pertencentes à classe de motivadores extrínsecos. Nessas manifestações percebe-se, de forma direta ou indireta, a preocupação com a avaliação cognitiva das atividades. Nesse sentido, verificamos que o aluno crê que a sua participação lhe proporcionará melhores resultados nesses processos avaliativos. Iniciativas como anotar o conteúdo ensinado pelo professor, tendo um caderno organizado em que possa concentrar as anotações realizadas e os resumos feitos pelo professor e, a partir desse material promover a fixação, às vezes por meio de memorização, manifesta o desejo de precaver-se e de estar preparado para os momentos de cobrança, principalmente em disciplinas nas quais têm maiores dificuldades.

Como se percebe, eles desenvolvem a sua intuição para a realização de determinadas atividades, nas quais o professor desenvolve um trabalho de organização do conhecimento, seja pela realização de problemas/exercícios e aplicações diversas dos conteúdos, seja pela apresentação de resumos, nos quais evidencia aspectos importantes relacionados aos temas, os quais, serão alvo de cobranças em avaliações. Nessas situações, a motivação para o seu envolvimento nas atividades, com empenho especial e atenção redobrada, está, em geral, relacionado aos resultados que isto lhe trará. Por isso, é importante ter o conteúdo direcionado ou estar atento ao que e como será cobrado.
Esta forma de participação e envolvimento na realização de tarefas em função dos resultados que ela trará, como notas, elogios ou prêmios, é característica de motivação extrínseca [7]. No ambiente escolar, este é o caso quando o aluno está fundamentalmente dedicado a obter boas notas e para isso passa a dedicar-se prioritariamente às atividades pela resposta que as mesmas podem fornecer nas avaliações. Se a memorização da fórmula e a internalização de determinado conceito ocorre de forma literal e arbitrária 2, apenas para que o aluno possa obter uma nota boa na prova a aprendizagem não é significativa e ele age apenas movido por motivadores extrínsecos.

No que se refere à motivação extrínseca, como relata Guimarães [7], deve-se levar em conta que ela predomina nas atividades desenvolvidas pelos indivíduos em sociedade. No contexto escolar, ela destaca-se na avaliação, uma vez que os alunos, ao almejar bons resultados, passam a se envolver ativamente nessas atividades, ainda mais que grande parte dos professores entende que essa forma de motivar é a mais adequada, ou, ao menos, a mais fácil de ser aplicada.

Um aspecto importante a ser salientado é que uma determinada atividade pode ser iniciada a partir de um motivador intrínseco, em função, por exemplo, da curiosidade que a proposta tenha despertado no aluno, mas, no decorrer do seu desenvolvimento esse caráter acabe por se perder devido às dificuldades inerentes à mesma. Nesse caso, a motivação extrínseca pode ser determinante para a conclusão da tarefa [11].

Um outro aspecto apresentado por Lepper, Corpus e Iyengar [24], é que a motivação intrínseca e a motivação extrínseca coexistem em sala de aula e que o mais importante é analisar a frequência de cada comportamento. Em relação ao envolvimento extrínseco dos estudantes com a escola, os autores sugerem que, com o avanço nas séries, as pressões externas, a competição e a busca por recompensas aumentam, o que, por suposição, aumentaria a motivação extrínseca. Além disso, é de considerar que o aluno possa envolver-se em uma atividade pelo prazer inerente e ao mesmo tempo estar atento às consequências extrínsecas deste envolvimento.

\section{Considerações Finais}

A motivação é resultado de complexas interações do indivíduo com o seu ambiente sociocultural que a influenciam de diversas formas. No contexto escolar, os fatores determinantes estão inseridos na sala de aula, que fornece o contexto para a orientação da motivação dos alunos. A utilização de adequadas estratégias de ensino pelo professor pode, portanto, determinar de modo decisivo incentivando e influenciando esta orientação. A motivação intrínseca tem sido apontada como um importante mediador no processo de aprendizagem, por isso, para propiciar uma aprendizagem significativa o professor pode e deve utilizar-se de estratégias de ensino 
que promovam a autonomia e a maestria, em uma esfera de intenso contato interpessoal.

O presente estudo investigou a opinião dos alunos em relação a cinco estratégias de ensino bastante utilizadas por professores de Física, mas que são de larga utilização em outras disciplinas de ensino médio, principalmente da área de ciências naturais. As aulas ministradas por meio dessas estratégias forneceram o pano de fundo para também expor aspectos determinantes das orientações motivacionais apresentadas pelos alunos participantes da pesquisa.

Atividades que promovem sensação de prazer, que estejam vinculadas ao lúdico e à novidade, que estimulem a curiosidade e a fantasia possuem grande potencial no que se refere a engajar os alunos nas tarefas e são consideradas motivadoras intrínsecas. No entanto, mesmo quando a componente principal de tais atividades esteja ligada ao entretenimento, é preciso considerar no planejamento das mesmas o desenvolvimento de competências e habilidades que são os objetivos primordiais do processo de ensino. Nesse sentido, é necessário ter em mente que elas devem ser geradoras de conhecimento, de modo que, em determinadas situações imagine-se que o aluno aprende divertindo-se, sendo este, possivelmente o maior desafio do professor.

O estudo revelou a presença de aspectos motivacionais em um amplo espectro, envolvendo características de motivação intrínseca, distribuída entre as várias dimensões ou categorias e de motivação extrínseca. Além disso, as diferentes estratégias são consideradas motivadoras para os alunos em função de diferentes aspectos e um mesmo aluno também oscila entre os extremos do espectro mencionado, revelando uma orientação motivacional mista.

É importante enfatizar que a avaliação da motivação dos alunos no contexto escolar, pela complexidade que o tema envolve, demanda análises bastante elaboradas e a utilização de instrumentos construídos e testados a partir de critérios teóricos bem fundamentados. Como se percebe na literatura especializada, no entanto, pesquisas qualitativas, descritivas, possuem um papel importante para o conhecimento dos alunos e podem contribuir para solucionar ou reduzir problemas enfrentados pelos professores.

Nesse sentido, também são importantes as pesquisas para propor e avaliar estratégias de ensino, que envolvam diferentes recursos didáticos, e a melhoria na motivação que podem causar nos alunos, bem como as respectivas influências da aprendizagem significativa que proporcionam.

\section{Referências}

[1] S. Silva, V.F. Neto e A.M.P. Carvalho, em: Questões atuais no ensino de ciências, organizado por R. Nardi (Escrituras, São Paulo, 1998).

[2] M.A. Moreira, Aprendizagem significativa (Editora da Universidade de Brasília, Brasília, 1999).
[3] P.R. Pintrich e D.H. Schunk, Motivation in education theory, research and applications (Prentice Hall, Englewood Cliffs, 1996).

[4] E.J. Murray, Motivação e emoção (Guanabara-Koogan, Rio de Janeiro, 1986).

[5] S.A. Harter, A scale of intrinsic versus extrinsic orientation in the classroom (University of Denver, Denver, 1980).

[6] C.N.M.F. Lima e A.M. Nacarato, Educ. em Rev. 25, 241 (2009).

[7] S.E.R. Guimarães, em: A motivação do aluno, editado por J.A. Bzuneck e E. Boruchovitch (Vozes, Petrópolis, 2001), p. 37.

[8] M.L.M.F. Paiva e E. Boruchovitch, Psicol. em Estud. 15, $381(2010)$

[9] E.L. Deci e R.M. Ryan, Intrinsic motivation and selfdetermination in human behavior (Plenum Press, New York, 1985).

[10] M.E. Martinez e E. Haertel, Sci. Educ. 75, 471 (1991).

[11] C.E. Laburú, Cad. Bras. Ensino Física 23, 382 (2006).

[12] A. Zabala, A prática Educativa Como ensinar (Artmed, Porto Alegre, 1998).

[13] L.G. Anastasiou e L.P. Alves (orgs), Processos de ensinagem na universidade. Pressupostos para as estratégias de trabalho em aula (Editora Univille, Joinville, 2004), p. 67 .

[14] A.T. Borges, Cad. Bras. Ensino Física 19, 2 (2002).

[15] C. Fiolhais e J. Trindade, Rev. Bras. Ensino Física 25, 259 (2003).

[16] http://phet.colorado.edu/

[17] M.D.P. Echeverría e J.I. Pozo, A solução de problemas: aprender a resolver, resolver para aprender (Artmed, Porto Alegre, 1998), p. 13.

[18] A.N.S. Trivinos, Três enfoques na pesquisa em ciências sociais: o positivismo, a fenomenologia e o marxismo (Atlas, São Paulo, 1987).

[19] N.K. Denzin e Y.S. Lincoln, O planejamento da pesquisa qualitativa (Penso, Porto Alegre, 2006).

[20] L. Bardin, Análise de conteúdo (Edições 70, Lisboa, 2007).

[21] M. Bauer e G. Gaskell, Pesquisa quantitativa com texto, imagem e som: um manual prático (Vozes, Petrópolis, 2002).

[22] M. Weber, Metodologia das ciências sociais (Cortez, São Paulo, 1995).

[23] L.D. Bordenave e A.M. Pereira, Estratégias de ensinoaprendizagem (Vozes, Petrópolis, 1993).

[24] M.R. Lepper, J.H. Corpus e S.S. Iyengar, J. Educ. Psychol. 97, 184 (2005). 